\title{
Reviewing outcomes of psychological interventions with torture survivors: Conceptual, methodological and ethical Issues
}

\author{
Nimisha Patel, Prof.*, Amanda C de C Williams, PhD**, Blerina Kellezi, PhD***
}

\begin{abstract}
Background: Torture survivors face multiple problems, including psychological difficulties, whether they are refugees or remain in the country where they were tortured. Provision of rehabilitation varies not only with the needs of survivors and resources available, but also with service models, service provider preferences and the local and country context. Despite increasing efforts in research on effectiveness of psychological interventions with torture survivors, results are inconclusive.
\end{abstract}

Methods: We undertook a Cochrane systematic review of psychological, social and welfare provision, with meta-analysis to best estimate efficacy. The process raised conceptual, methodological and ethical issues of relevance to the wider field.

Findings: We searched very widely, but

\footnotetext{
*) International Centre for Health and Human Rights and Professor of Clinical Psychology, University of East London, UK

$\left.{ }^{\star \star}\right)$ Research Department of Clinical, Educational and Health Psychology, University College London, UK $\star \star \star)$ School of Social Sciences, Nottingham Trent University, UK
}

Correspondence to: amanda.williams@ucl.ac.uk rejected hundreds of papers which recommended treatment without providing evidence. We found nine randomised controlled trials, from developed and under-resourced settings. All conceptualised survivors' problems in psychiatric terms, using outcomes of post-traumatic stress symptoms, distress, and quality of life, by self-report, with or without translation or unstandardised interpretation, and with little mention of cultural or language issues. None used social or welfare interventions.

Four related studies used narrative exposure therapy (NET) in a brief form, and without ensuring a safe setting as recommended. Five used mixed methods, including exposure, cognitive behavioural therapy, and eye movement desensitisation. Combined, the studies showed no immediate improvement in PTSD, distress, or quality of life; at six months follow-up, a minority showed some improvement in PTSD and distress, although participants remained severely affected.

Conclusions: While applauding researchers' commitment in running these trials, we raise ethical issues about exposure in particular, and about the effects of shortcomings in methodology, particularly around assessment using unfamiliar cultural frameworks and language, and the lack of concern about dropout which may indicate harm. The 
issues addressed aid interpretation of existing research, and guide clinical practice as well as future studies evaluating its effectiveness.

Keywords: intervention evaluation, systematic review, ethical challenges, interpretation, torture survivors

\section{Introduction}

Many survivors of torture remain in the countries where they were tortured and others seek refuge in other countries: the IRCT $(2010)^{1}$ estimated around 400,000 torture survivors living in the European Union alone, with similar estimates in the USA over 20 years ago. ${ }^{2}$ Globally, it is difficult to reliably estimate the numbers of torture survivors, but they include those still living in countries where torture takes place as well as those who are refugees and asylum seekers. Some survivors may be able to seek and access help with problems related to their experiences of torture, of flight, and of seeking asylum and trying to settle. Other torture survivors may be offered treatment or support by international or local NGOs based in the same region as their country of origin, whilst those remaining in the countries where they were tortured may access rehabilitation services where available, or rehabilitation programmes in countries undergoing transitional justice processes.

The interventions offered by NGOs or state healthcare services or in rehabilitation programmes vary according to local needs, client population (e.g. refugees, asylum seekers, or 'in-country victims' of torture) and the nature of the torture survivor needs, which can be complex and multiple, particularly around health and legal protection. Services and interventions are often multimodal and offered simultaneously, within a 'whole person approach' - described as a holistic approach. They may also vary according to the local political, social, economic and cultural context. Additionally, interventions offered vary depending on the theoretical preferences, professional training and the philosophical stance of practitioners and services. ${ }^{3}$

An important and enduring question in the field is: what is the best evidence on the efficacy of the various interventions used in these services or programmes? Since a significant proportion of those services offer psychological, social and welfare interventions, we took this as our focus and chose to do a systematic review within the Cochrane system $^{\mathrm{i}}$ because this requires that review methods are of a high standard and transparent, and that data from trials are meta-analysed and interpreted in particular ways to minimise bias. This paper is based on some of the methodological and ethical issues which arose during the review.

Since we found no randomised controlled trials in social or welfare interventions, our review is only of psychological interventions. The studies, nine randomised controlled trials, are summarised in Table 1 and the results in Table 2 . There were many difficult decisions to make about eligibility of trials and handling of data, and these raised wider issues about the way that psychological problems of torture survivors are conceptualised and assessed in studies, as well as what interventions are used with survivors. We will address each of these issues in turn.

\footnotetext{
${ }^{\mathrm{i}}$ The Cochrane Collaboration www.cochrane.org is an international not-for-profit organisation preparing, maintaining and promoting the accessibility of systematic reviews of the effects of health care.
} 
Table 1: Characteristics of included studies

\begin{tabular}{|c|c|c|c|c|c|c|}
\hline $\begin{array}{l}\text { First author } \\
\text { and reference }\end{array}$ & setting & treatment & control & $\begin{array}{l}N \text { at start } \\
\text { and end }\end{array}$ & $\begin{array}{l}\text { Improved with } \\
\text { treatment }(C=\mathcal{E} \\
\text { control) }\end{array}$ & $\begin{array}{l}\text { not improved } \\
\text { with treatment }\end{array}$ \\
\hline Bichescu $^{48}$ & $\begin{array}{l}\text { Romanian } \\
\text { clinic }\end{array}$ & $\begin{array}{l}\text { Individual } \\
\text { NET }\end{array}$ & $\begin{array}{l}\text { Psycho- } \\
\text { education }\end{array}$ & 18,18 & $\begin{array}{l}\text { PTSD symptoms, } \\
\text { PTSD diagnosis, } \\
\text { depression }\end{array}$ & - \\
\hline $\begin{array}{l}\text { Hensel- } \\
\text { Dittman }^{54}\end{array}$ & $\begin{array}{l}\text { German } \\
\text { trauma clinic }\end{array}$ & $\begin{array}{l}\text { Individual } \\
\text { NET }\end{array}$ & $\begin{array}{l}\text { Stress inocula- } \\
\text { tion }\end{array}$ & 28,21 & $\begin{array}{l}\text { PTSD diagnosis } \\
\text { (C), PTSD } \\
\text { symptoms }\end{array}$ & Depression \\
\hline Igreja $^{50}$ & $\begin{array}{l}\text { Mozambican } \\
\text { refugee camp }\end{array}$ & $\begin{array}{l}\text { Individual } \\
\text { testimony }\end{array}$ & No treatment & 137,131 & $\begin{array}{l}\text { PTSD symptoms } \\
\text { (C), psychiatric } \\
\text { symptoms (C), } \\
\text { nightmares (C) }\end{array}$ & - \\
\hline Neuner ${ }^{49}$ & $\begin{array}{l}\text { German } \\
\text { trauma clinic }\end{array}$ & $\begin{array}{l}\text { Individual } \\
\text { NET }\end{array}$ & $\begin{array}{l}\text { Treatment as } \\
\text { usual }\end{array}$ & 32,30 & PTSD symptoms & $\begin{array}{l}\text { PTSD } \\
\text { diagnosis, } \\
\text { depression, } \\
\text { pain }\end{array}$ \\
\hline Paunovic $^{53}$ & $\begin{array}{l}\text { Swedish } \\
\text { trauma clinic }\end{array}$ & $\begin{array}{l}\text { Individual } \\
\text { CBT }\end{array}$ & Exposure & 20,16 & $\begin{array}{l}\text { PTSD diagnosis } \\
\text { (C), PTSD } \\
\text { symptoms (C), } \\
\text { anxiety (C), } \\
\text { depression (C), } \\
\text { quality of life (C) }\end{array}$ & $\begin{array}{l}\text { World } \\
\text { assumptions }\end{array}$ \\
\hline Pokhariyal $^{83}$ & $\begin{array}{l}\text { Kenyan refugee } \\
\text { \& torture } \\
\text { survivor project } \\
\text { in Kenya }\end{array}$ & $\begin{array}{l}\text { Individual } \\
\text { 'trauma } \\
\text { processing' } \\
\text { incl. EMDR }\end{array}$ & Psychotherapy & 96,69 & $\begin{array}{l}\text { PTSD symptoms } \\
\text { (C) }\end{array}$ & - \\
\hline Schauer $^{55}$ & $\begin{array}{l}\text { German } \\
\text { trauma clinic }\end{array}$ & $\begin{array}{l}\text { Individual } \\
\text { NET }\end{array}$ & $\begin{array}{l}\text { Treatment as } \\
\text { usual }\end{array}$ & 32,32 & PTSD symptoms & - \\
\hline Ter Heide ${ }^{84}$ & $\begin{array}{l}\text { Dutch } \\
\text { trauma clinic }\end{array}$ & $\begin{array}{l}\text { Individual } \\
\text { EMDR }\end{array}$ & Stabilisation & 20,10 & PTSD diagnosis & $\begin{array}{l}\text { Trauma } \\
\text { symptoms, } \\
\text { anxiety, } \\
\text { depression, } \\
\text { quality of life }\end{array}$ \\
\hline Yeomans $^{51}$ & $\begin{array}{l}\text { Burundi } \\
\text { refugee camp }\end{array}$ & $\begin{array}{l}\text { Group } \\
\text { reconcilia- } \\
\text { tion \& } \\
\text { education }\end{array}$ & Waiting list & 124,117 & PTSD symptoms & Distress \\
\hline
\end{tabular}


Table 2: Outcomes post-treatment and follow-up

\begin{tabular}{|c|c|c|}
\hline Outcome & Post-treatment & Follow-up \\
\hline Distress & $\begin{array}{l}\text { SMD }=-0.15, \text { CI }-0.39-0.09 \\
5 \text { studies, } 290 \text { people } \\
\text { Mixed anxiety and depression }\end{array}$ & $\begin{array}{l}\text { SMD }=-0.63, \mathrm{CI}-1.07--0.19 \\
4 \text { studies, } 86 \text { people } \\
\text { Depression }\end{array}$ \\
\hline $\begin{array}{l}\text { Post-traumatic stress disorder } \\
\text { symptoms }\end{array}$ & $\begin{array}{l}\mathrm{SMD}=-0.30, \mathrm{CI}-0.66-0.06 \\
7 \text { studies, } 351 \text { people }\end{array}$ & $\begin{array}{l}\mathrm{SMD}=-0.52, \mathrm{CI}-0.97--0.07 \\
4 \text { studies, } 86 \text { people }\end{array}$ \\
\hline $\begin{array}{l}\text { Post-traumatic stress disorder } \\
\text { diagnosis }\end{array}$ & $\begin{array}{l}\text { Odds ratio }=0.28, \text { CI } 0.06-1.36 \\
3 \text { studies, } 52 \text { people }\end{array}$ & No results \\
\hline Quality of life & $\begin{array}{l}\mathrm{SMD}=0.70, \mathrm{CI}-0.11-1.51 \\
2 \text { studies, } 26 \text { people }\end{array}$ & No results \\
\hline
\end{tabular}

SMD = standardised mean difference, calculated by difference in mean outcome between groups/standard deviation of outcome among participants. A minus number indicates a reduction in score.

$\mathrm{CI}=95 \%$ confidence intervals. If these include 0 , then the change is not statistically significant.

SMD is also referred to as 'effect size', for which $<0.3$ is described as small, $0.4-0.6$ as moderate, and $>0.7$ as large.

\section{Conceptual issues}

Torture survivors are defined as such by their experience of torture (as defined by the United Nations Convention against Torture and Other Cruel, Inhuman or Degrading Treatment or Punishment (Article 1) ${ }^{4}$ rather than as a distinct, homogenous client group defined by health or specific psychological problems. However, in most studies, torture survivors were predominantly defined and selected, not by their experiences, but by a diagnosis of post-traumatic stress disorder (almost to the exclusion of other psychological problems such as depression), and of the wider social, economic and other difficulties related to their experience of torture, and for some, their experience of being an asylum seeker or refugee.

Interestingly, two anonymous reviewers of our review protocol suggested that if one rejected 'torture syndrome' as the way to identify survivors with health problems, then the only alternative was to fit their symptoms to existing nosologies. However, there are many other ways in which torture may impact on individuals and families, distress which can manifest in ways which do not fit, or are not restricted to, existing nosologies of psychopathology. Reports of difficulties in physical and psychological health, in family and wider social relationships, and in establishing a new and valued life after torture, are widespread and consistent. ${ }^{5-10}$ It is not unexpected either to find torture survivors' accounts of profound existential struggles, and fundamental questions about what it is to be human (e.g. ${ }^{11-13}$ ). Studies of the impact of external factors are rather more recent: ongoing stressors such as detention, ${ }^{14}$ homelessness, uncertainty about asylum outcome, and racism, ${ }^{15,16}$ although these post-exile conditions can be major predictors of current distress. ${ }^{17-19}$ Even rarer are studies examining the impact of the recovery environment, justice and reparation on recovery and well-being. ${ }^{20}$

We will not repeat here the continuing debates about the limitations of the application of diagnoses based on Eurocentric constructs such as post-traumatic stress to 
torture survivors from diverse cultural backgrounds, ${ }^{6,20-24}$ and broader arguments about the validity of psychiatric diagnoses. ${ }^{25-30}$ However, we note that the new edition of DSM-5 is questionable with respect to scientific validity and clinical utility. ${ }^{31,32}$ For example, the reformulated diagnosis of post-traumatic stress disorder has four symptom clusters rather than three, and 20 symptoms overall rather than 17 ; but broadening its criteria has created unmanageable heterogeneity, with 636,120 possible ways to meet the diagnostic criteria. ${ }^{33}$ It is not yet clear whether many people with significant distress, including torture survivors, still fail to meet them. Indeed, the absence of a diagnosis may lead to a false assumption that the person has not experienced torture, or that they are not suffering and in need of support. This can have important implications for establishing refugee status and the right to rehabilitation and reparation. In research, the absence of a diagnosis, in spite of distress, may exclude some torture survivors from studies.

A notable effect of the focus almost exclusively on PTSD in studies with torture survivors is that survivors are often combined with other client groups in trials and reviews of treatment literature (e.g. ${ }^{34,35}$ ). In studies conducted in neighbouring countries to which the torture survivors had fled, they were often combined with other refugees from civil conflict and humanitarian crises who might not have experienced torture, whereas in studies conducted, for example, in Europe, torture survivors were most often part of a narrow clinic population who met the criteria for the specialist clinic or service and who could access those services. In both these settings, the commonly used checklist summaries of relevant experiences tend to underestimate the torture experience. ${ }^{36,37}$ This is compounded by the difficulties for many torture survivors in disclosing torture, such as fear of recrimination, shame, stigma, and other reasons. The studies we found that included only torture survivors were predominantly single cases or case series (for reviews see ${ }^{6,38}$ ), which were potentially of value but outside our requirement for randomisation. Such studies often put more weight on contextualising psychological and wider problems in the current and past experience and situation of the individual, and in the broader sociopolitical context, than did randomised trials where torture survivors were mixed with other traumatised people. But disappointingly, these single cases or case series surprisingly often consist of the survivors' histories and difficulties at the start of treatment, followed by an account of the authors' preferred treatment methods, but no qualitative or quantitative account of the outcome or reflection on methods.

We are critical of the poverty of this very extensive literature on individuals or families as it offers little to clinicians looking for information on treatment process and effectiveness and suitability of particular interventions for torture survivors. However, neither do we subscribe to the apparent equating, by virtue of common symptoms or diagnosis, of torture survivors' psychological problems with those of, for example, road traffic accidents or physical assaults (where individuals had usually experienced a single traumatic event). This was usually the largest group in developed world clinic studies. The exception to this, of course, is survivors of domestic violence and sexual abuse, but we did not find any studies which combined these groups with torture survivors for treatment.

\section{Methodological issues}

Cochrane reviews require that the protocol for the search, study selection, data extrac- 
tion, and data analysis is published and, with any exceptions explicitly noted, followed in the full review. We had to make several difficult decisions, each of which raised conceptual issues and brought to our notice literature of which we had been unaware (see our protocol and review ${ }^{39}$ ).

We decided to search not only in the usual peer-reviewed journals but also in the 'grey literature' which is not abstracted in mainstream databases and may not be abstracted at all. For instance, treatment studies could be published in an annual report of a project which had now closed, or in chapters in books which were hard to access. Erring on the side of including everything that we could not be certain should be excluded, we collected about 1,500 papers whose titles promised much but which were very largely case studies with little or no data, as described above. Among them were some imaginative interventions, some run in very straitened settings, introducing help as needs were identified by the target community. None of these were randomised.

The studies which met our inclusion criteria, therefore, came from academic publications, but by no means were all the trials conducted in developed countries. Those which treated torture survivors as part of a population which had been subjected to organised violence and many documented human rights violations in conflict amounting to torture, such as in Rwanda, were included. Those which treated torture survivors as a minority within a group of people traumatised by other events during war and flight (e.g. ${ }^{40}$ ), or acts of terrorism such as 9/11 (e.g. ${ }^{41}$ ), or military experience (e.g. ${ }^{42}$ ), were excluded. Our discussion about excluding studies of those with combat experiences during conflict was protracted, since it is by no means coterminous with torture, however traumatising. A particular case was that of Vietnam war veterans, about whom there are many published treatment trials. Those who were prisoners of war were likely at least to have witnessed torture, but the political context was very different from that of wars in the Democratic Republic of Congo or Bosnia, for example. Most studies, even if they reported experiences such as being a prisoner of war or witnessing torture, did not analyse these participants separately from others who saw active service but were not tortured. We hoped to be able to contrast those studies only of torture survivors with those in which torture survivors were a majority alongside survivors of armed conflict, as the question of difference is in part an empirical one, but there were not sufficient studies to allow this.

Each of these conceptual issues influenced the decisions on inclusion or exclusion of studies, and on judging quality of studies and external validity of their findings.

Readers who disagree with our concerns may also disagree with those decisions made, and therefore would have reviewed a different set of studies. Whilst the authors were inclusive, too, about what was considered to be psychological, social or welfare interventions, aware that many NGOs use a wide variety of therapies and therapeutic interventions, including art, drama, music and dance, the studies which met the inclusion criteria in fact used a relatively narrow range of types of intervention, such as narrative exposure therapy (NET), cognitive and behaviour therapy (CBT), and eye movement desensitisation and reprocessing (EMDR).

A further decision to make at the protocol stage of a systematic review is to specify outcomes, and while this draws to a certain extent on familiarity with the literature, Cochrane also encourages reference to fundamental principles of 
treatment - such as including adverse events as an outcome - and to the likely needs of the population. Once there is a shortlist of outcomes, from symptom counts to overall well-being or participation in wider society, decisions must be made about whether and how to combine them. For instance, is it crucial to separate 'anxiety' and 'depression' or are they best combined as 'distress'? If the latter, then should post-traumatic stress also be included in 'distress'? To an extent, we were influenced in our tendency to combine rather than to segregate these outcomes by our sense of uncertainty about whether measurement scales used in the studies across cultural and language differences really told us what their titles claimed, an issue discussed further below.

\section{Culture, language and measurement}

It was hoped that an assessment would be possible of the effectiveness of various interventions in terms of the needs and health problems of torture survivors commonly reported in the literature. ${ }^{6,43}$ This can, of course, include a range of health problems, such as: impairment and disability, social support, interpersonal and family relationships and functioning, shame and guilt, substance misuse, self-esteem, feeling disempowered, lacking agency and control in one's life, having lost a sense of meaning and purpose in one's life and having no sense of justice and no validation and worth as a human being. In addition, those seeking asylum can struggle enormously with the asylum determination process, including being deprived of the right to work or education, not being able to access health and other services, adaptation to a new culture, learning of a new language, loss of family and relationships, fear for the fate of those left behind, or fear of return to the country of origin or the place they suffered torture. Instead, a narrow range of measurement tools was found which had been developed in the West for Western, English-speaking populations and standardised on the same populations, inevitably instantiating Western psychological models based on dualist understandings of health, in contrast to most non-Western conceptualisations of health and wellbeing which encompass emotional, physical, spiritual, familial, social and political status. For those who support the view that the psychiatric categories as represented in the current Diagnostic and Statistical Manual (DSM) are universally valid, this is not a problem. For those who do not support this view, or who have doubts, the lack of attempts to revalidate or even to examine how tools perform when translated and used in non-Western populations is disturbing, ${ }^{7,16,21,23,44}$ and leads many to conclude that the tools have no construct validity (e.g. ${ }^{15,37,44-46}$ ).

Almost all measurement tools in the studies we reviewed were self-report scales, variously completed by trial participants in their own first language, in the host country language, by direct verbal response to questions from a form or from a researcher translated on the spot by trained interpreters or by informal assistants. Most studies were unconcerned with issues beyond a match of language of assessment to language of participants. The most common were PTSD scales, followed by depression and anxiety. Only two of the nine studies assessed quality of life. For all of the studies, then, issues can be raised concerning the suitability of content, the reliability and validity in the population, of sensitivity to change, and, lastly, of social and cultural norms about disclosure and responding to questions, particularly when in the presence of an interpreter and a research worker. 


\section{Treatment and ethical issues}

The foregoing description of the processes by which the eventual trial set emerges may seem over-detailed, but one of the guiding principles of Cochrane reviews is their replicability, by virtue of the transparency of the review methods and process, and in contrast to narrative reviews whose methods are rarely explicit. Thus, the nine trials which qualified, and all of which provided data for meta-analysis, are not representative of the range of interventions for torture survivors, but are the least problematic with respect to all the difficulties of interpreting uncontrolled treatment trials and disentangling the effects of being in any treatment from the effects of being in a particular treatment. Any treatment in this context nevertheless presumes that an alternative treatment of some credibility was given (such as psychoeducation $^{48}$ ), or 'treatment as usual' (e.g. ${ }^{49}$ ), is provided, rather than nothing (used by only one trial ${ }^{50}$ ); even being on a waiting list ${ }^{51}$ can have weak therapeutic effects from its promise of help in the future. ${ }^{52}$

Six of the nine studies in our review were conducted in Europe, five on mixed refugee populations (although some awaiting asylum decisions) and one in Romania on survivors of torture experienced as political prisoners; and, three were run in different African countries of which two were with refugee populations and one with a mixture of refugees and nationals. Only one, from a Swedish clinic, ${ }^{52}$ had a minority of participants identified as torture survivors, with the rest defined as traumatised by organised violence such as witnessing a massacre, or experiencing death threats.

As can be seen in Table 1, four interventions were of the same school and five were combinations of several methods. The four which used NET ${ }^{48,49,54,55}$ may well have used versions of the same manual to guide individual narrative exposure treatment, elements of this were used in two further trials of testimony therapy ${ }^{50}$ and 'trauma healing, ${ }^{51}$ NET is based on Testimony Method $^{56}$ which was developed specifically within a human rights framework as a 'therapeutic instrument' for work with torture survivors in Chile. It was subsequently adapted in Germany for work with refugees, drawing on cognitive behavioural therapy and named NET ${ }^{57}$ NET draws on exposure methods incorporated in cognitive and behavioural packages (e.g. ${ }^{58}$ ) for fear and anxiety-related disorders, ${ }^{59}$ aiming both to habituate the survivor to thoughts and cues related to traumatic events while integrating the experience of both into a personally contextualised narrative. Despite significant conceptual and philosophical differences between Testimony Method and NET, it is suggested by some that, like the Testimony Method, NET produces a coherent narrative account of torture which may then, apparently, be used in processes of justice or claiming asylum. ${ }^{60}$ There is little evidence for this in many trials or in clinical practice.

The use of NET with torture survivors appears to be driven more by the assertion that it is a 'brief' therapy than by evidence, which still remains rather thin and comes almost entirely from one group of researchers, a point noted by other reviewers. ${ }^{57,} 60-62$ Its use did develop in low income countries, with briefly trained lay therapists or $\mathrm{PhD}$ students rather than qualified healthcare professionals as is usually the case in high income countries. This, however, makes its use alongside the PTSD diagnostic label more puzzling, ${ }^{62,63}$ since the PTSD construct medicalises the impact of torture or other related trauma, stripping it of its societal context $\mathrm{t}^{62}$ and ignoring parallel and ongoing stresses and traumas experienced in those country settings, for example, the 
impact of poverty, land and home insecurity, lack of food and safety, continued impunity, and the threat of further conflict and torture. A focus on narrative therapy has also been criticised for diverting attention from the right to compensation (as a form of reparation), and from individuals' own resilience. ${ }^{64}$

Clinical guidelines on the use of NET appear to refer to somewhat simpler trauma than that of torture, yet treatments provided to torture survivors were often briefer than recommended by those guidelines, ${ }^{65}$ and lacked the number of sessions to establish rapport and safety that are recommended before trauma-focused treatment begins. ${ }^{58,65}$, ${ }^{66}$ Torture survivors rarely if ever have the stability and safety in their current situation assumed by the guidelines; it cannot be assumed even in the two studies in which participants had permanent residence in the country that they had social and economic security. Other questions have been raised about the effectiveness of NET for people with marked dissociation. ${ }^{67}$ Extrapolation from methods developed for a single trauma in an otherwise stable life does not only affect NET treatment packages; some of the cognitive treatment literature also has an emphasis on correcting 'distorted beliefs' and 'misrepresentations' of the (assumed) relatively safe world. ${ }^{68}$ This may apply poorly to the world in which the torture survivor lives, and may appear to be disbelieving of, or indifferent to, their experience of torture.

In our systematic review there were additional issues raised about some of the studies concerning ethics. One issue is the use of brief exposure methods without contextual understanding of torture. Some of the most impressive evidence for the benefits of brief exposure comes from the work of Basoglu with earthquake survivors, ${ }^{69}$ where the trauma and recovery processes are shared by the entire community. This is very different from torture. Torture is not a natural disaster, or a shared experience, but deliberate, systematic, state-sanctioned violence, which impacts on, generates and perpetuates mistrust and fear amongst torture survivors, their families and communities, and undermines the establishment of personal relationships important for recovery. Torture survivors, additionally, usually experience multiple torture and other traumatic experiences of violence and threat of harm. For some, stresses of seeking asylum and living in exile, over long time periods, are compounded by other ongoing violence, including abuse, rape, and domestic violence. It could be queried how these can be meaningfully and ethically reduced to few enough cues for successful exposure, or few enough events for a meaningful narrative to be constructed.$^{58}$ It could also be queried how exposure, particularly in the hands of a briefly trained health or lay worker, can avoid or address the risk of re-traumatisation, perhaps reminiscent of abuse previously experienced, and client dropout in a worse state than when she or he entered treatment. Nor is it clear the extent to which exposure, rather than the process of integrating experiences within the political/ societal context, brings about a reduction in symptoms ${ }^{67}$ or for that matter changes in the environment and context of the survivor, for example, in the form of resettlement as a refugee, or secure housing and increased security.

Further, for all the reference to experimental findings on PTSD, understanding of the phenomenon seems somewhat skewed by wishful thinking that associations are unlearned or obliterated. But the animal literature ${ }^{70}$ makes very clear that extinction of fearful responses consists of learning an exception to the association between cue(s) and trauma, and the original cue-fear associations continue to compete with new 
associations. Context can have significant effects on that competition, making for difficulties in generalisation and overly optimistic estimates of treatment effectiveness.

Another issue of relevance in methods focussing specifically on exposure is the ethical dimension of exposure where the experience of torture included sexual violence. One may ask, how can sexual torture for example, be addressed in exposure work in a way which is ethical, gender-sensitive and appropriately and meaningfully addresses gender and other power dynamics? Other authors have also raised ethical concerns (see reviews ${ }^{57,63}$ ), but none of the studies in our systematic review mentioned any ethical issues or assessed adverse events. Some dropout was attributed to symptom worsening, yet without any discussion of this.

The relatively uncritical enthusiasm for NET despite weakness of treatment trials with torture survivors is surprising, and here the difference between the conclusions of our systematic review and the reviews of Crumlish and O'Rourke, ${ }^{71} \mathrm{McF}$ arlane and Kaplan, ${ }^{62}$ and Nicholl and Thomson ${ }^{72}$ must be noted. All, with reservations, are positive about existing psychological treatment efficacy, with CBT and NET most often identified. We recommend these reviews to readers who wish to find an extended description of the other methods mentioned here, such as EMDR and CBT. Robjant and Fazel $^{60}$ in their review of NET refer to symptom remission which is maintained over the medium to long term, while in our meta-analysis we found no immediate benefits either for PTSD or depression, and medium term gains in both outcomes achieved only reduced severity of symptoms but nothing close to a level which would be considered a good clinical outcome. Importantly, the changes in symptoms, where found, were not immediately after treatment, as would be expected in exposure treatment, but at follow-up at a period considerably after the end of treatment - traditionally a method used to assess the maintenance of any improvements found post-treatment.

The improvements shown at follow-up in the studies we reviewed are not explained by the authors, and there is no note of other possible factors in the period between post-treatment and follow-up which could have accounted for the improvement, such as positive changes in their economic or security context, living conditions, being resettled in another country as a refugee etc. Such methodological issues raise ethical concerns about lack of transparency and of adequate discussion of context.

Additionally, one of the concerns of Cochrane reviews is to identify bias and to understand its possible effects on trial findings. ${ }^{73}$ Some bias arises predominantly from trial methodology. These included for instance, method of sequence generation for randomisation, concealment of group allocation, attempts to mitigate the almost impossibility of blinding therapists or participants to treatment allocation, and assessment by third parties unaware of group allocation. Other bias is more related to treatment practice, and in particular either the internal validity of treatment (such as manualisation and adherence to protocol, or adequacy of therapist training to deliver the treatment), or its external validity (did results include all who started treatment, or only those who completed it?).

The nine trials included in the systematic review were mixed on these features, and none of the main techniques were found to be superior to the others. We were more concerned with further risks of bias which are less often discussed. One was therapist allegiance: investment in a particular therapy 
which is the active treatment compared with a control. Investment may run from preference or familiarity to vested interests in terms of ownership of therapeutic methods. It can add considerably to the persuasiveness of the active therapy when the same therapist delivers the control treatment in a more neutral manner. ${ }^{74}$ Four of the nine studies declared allegiance to NET, two using the same therapists to deliver both the active treatment and control arm.

Further sources of possible bias, raising ethical concerns, arose from the use of interpreters or interviewers who were sometimes interpreters and sometimes researchers whose questions were interpreted, both of which can influence responses given by participants. Assessment is difficult in this field, and no trial was able to assess by self-report in the participant's own language, the method least open to contextual influence and arguably more ethical. On-the-spot interpretation, and even clarification of items which are not understood at first, make for non-standard assessment even within the sample. Nor were interviewers or interpreters always blind to treatment allocation. We were also surprised by the lack of concern for cultural-conceptual and language authenticity and validity of assessment instruments, despite an accessible literature on methods of establishing linguistic validation as a minimum. ${ }^{75-77}$ Further, stigma related to reporting symptoms of poor psychological health tends to undermine rapport and inhibit disclosure of symptoms in interview situations: both lead to underassessment of these problems. ${ }^{15,37}$ These issues, examined in greater detail in our review, weakened our confidence in the findings of the trials.

\section{Conclusion}

A recent survey in the USA of torture survivor treatment centres ${ }^{78}$, albeit with a response from only about one quarter of eligible therapists, found treatment for traumatised survivors (identified in terms of PTSD by most) to be predominantly psychoeducation, supportive counselling, and CBT, with only one third using NET. In Europe many centres explicitly take a broad approach combining diverse methods ${ }^{79,80}$ : psychotherapeutic interventions from a range of models, including cognitive behavioural therapy or variants, psychodynamic and systemic therapies (including verbal, arts-based), family therapy and support, group support/therapy, and complementary approaches. In recognition of the diversity of interventions used in clinical practice - often in combination and simultaneously- for torture survivors, and the complexity of contextual factors which can influence outcomes, it seems important that outcome studies do not singularly focus on individual interventions. Nor should they focus only on specific diagnoses to assess effectiveness, nor rely only on randomised controlled trials which themselves have limitations. It may be that some of the enthusiasm for NET arises from the relative straightforwardness of evaluating it, compared to more holistic methods, and the emphasis on evaluation which often originates with the pressure for demonstrating value to funders.

The methodological and ethical challenges of conducting outcome studies in this field are not insignificant, requiring rigour in developing methods for meaningfully capturing change, and sensitivity to culture, gender and wider contextual factors, such as lack of safety, impunity, poverty, and discrimination, which impact on outcomes. These challenges are huge but are not insurmountable. The risk of not addressing them is greater in terms of the consequences for what is offered to survivors of torture by way of 'treatment'. 
Cochrane reviews end with recommendations for clinical practice and for research, based on findings of the review. Our conclusions for practice were that there was too little evidence, and it was too heterogeneous and of generally low quality, to recommend any particular treatment, that none showed immediate benefit, and that longer term gains were hard to interpret. Findings cannot be extrapolated to torture survivors without high PTSD symptom levels.

The interested reader is referred to the Cochrane review ${ }^{40}$ for a fuller account of research and practice implications. The small number and size of trials meant that we could not draw firm conclusions about treatment efficacy, nor about details of its timing or setting, about format (such as group vs individual), or about training of therapists. Better evaluation will need collaboration between trialists and more realism on the part of donors and funders about the resources required. However, even small trials could provide more information about the context of participants in trials, about their psychological and social status far beyond what can be described in terms of PTSD symptoms, about therapists and their training and background, and, about adverse effects of treatment and attrition. There are no easy solutions to the issues of suitable outcome tools that are culturally appropriate and available in the required languages, but there are recognised methods for authenticating assessment instruments and translating them, and these methods are rarely used. For further discussion of these issues and relevant methods, see Patel and Williams. ${ }^{81}$ In a larger framework, randomised controlled trials are not the only method to examine the efficacy of a treatment for a particular population, nor necessarily the best. Most importantly, the right to rehabilitation and reparation must guide interventions, as is evident in some non-randomised trials (e.g. ${ }^{82}$ ), so that they are designed by reference to the needs of participants not the preferences of trialists.

\section{Acknowledgements}

Oak Foundation Trust and International Centre for Health and Human Rights for funding the work underpinning this paper and the related Cochrane systematic review.

\section{References}

1. 26 June - International Day against Torture. The fight against torture: a key priority for the EU [Internet] 2007 June 26 [updated 2015 Oct 22; cited 2010 Feb 25]. Available from: http://europa.eu/rapid/pressReleasesAction. do? reference $=$ MEMO/07/254.

2. Jaranson JM. Government-sanctioned torture: status of the rehabilitation movement. Transcult Psychiat Res Rev. 1995;32:253-86.

3. Montgomery E, Patel N. Torture rehabilitation: reflections on treatment outcome studies. Torture. $2011 ; 21(2): 141-5$.

4. UN Convention against Torture and Other Cruel, Inhuman or Degrading Treatment or Punishment, 1984, New York.

5. Westermeyer J, Williams M. Three categories of victimization among refugees in a psychiatric clinic. In: Jaranson JM, Popkin MK, editors, Caring for victims of torture. Washington, DC: American Psychiatric Association, 1998:61-86.

6. Quiroga J, Jaranson JM. Politically motivated torture and its survivors: a desk study review of the literature. Torture. 2005;15:1-111.

7. Johnson H, Thompson A. The development and maintenance of post-traumatic stress disorder (PTSD) in civilian adult survivors of war trauma and torture: a review. Clinical Psychology Review. 2008 Jan 1;28(1):36-47.

8. Sjölund B, Kastrup M, Montgomery E, Persson AL. Rehabilitating torture survivors. J Rehabil Med. 2009;41:689-96.

9. Patel N. The psychologisation of torture. In: M Rapley, J Moncrieff, J Dillon, editors. De-medicalising misery: psychiatry, psychology and the human condition. London: Palgrave Macmillan, 2011, 239-55.

10. Steel Z, Chey T, Silove D, Marnane C, Bryant RA, van Ommeren M. Association of torture and other potentially traumatic events with mental health outcomes among populations exposed to 
mass conflict and displacement. JAMA. 2009

Aug 5;302(5):537.

11. Guzel A. Asiye's Story. London: Saqi Books; 2003.

12. Bould G. Conscience be my guide. London: Zed Books; 1991.

13. Frankl VE. Man's search for meaning. London: Beacon Press; 1962.

14. Steel Z, Silove D, Brooks R, Momartin S, Alzuhairi B, Susljik INA. Impact of immigration detention and temporary protection on the mental health of refugees. Brit J Psychiatry. 2006 Jan;188:58-64.

15. Mahtani A. The right of refugee clients to an appropriate and ethical psychological service. Int J Human Rights. 2003;7:40-57.

16. Patel N. Torture, psychology and the 'war on terror': a human rights framework. In: Roberts $\mathrm{R}$, editor. Just war: psychology and terrorism. Rosson-Wye, UK: PCCS Books; 2007.

17. Miller KE, Weine SM, Ramic A, Brkic N, Bjedic ZD, Smajkic A, Boskailo E, Worthington G. The relative contribution of war experiences and exile-related stressors to levels of psychological distress among Bosnian refugees. J Traum Stress. 2002 Oct;15:377-87.

18. Gorst-Unsworth C, Goldenberg E. Psychological sequelae of torture and organised violence suffered by refugees from Iraq. Trauma-related factors compared with social factors in exile. $\mathrm{Br} \mathrm{J}$ Psychiatry. 1998 Jan;172:90-4.

19. Porter M, Haslam N. Internally displaced persons: a meta-analysis associated with mental health of refugees and predisplacement and postdisplacement factors. JAMA. 2005 Aug 3;294(5):602-12.

20. Patel N. Justice and Reparation for torture survivors. JCPCP. 2011;11(3):135-47.

21. Bracken P, Giller J, Summerfield D. Psychological responses of war and atrocity: Limitations of current concepts. Soc Sci Med. 1995 Apr;40(8):1073-82.

22. Bracken PJ, Celia P. Rethinking the trauma of war. London: Save the Children with Free Association Books; 1998.

23. Patel N. Clinical psychology: reinforcing inequalities or facilitating empowerment? Int J Human Rights. 2003;7(1):16-39.

24. Summerfield D. The invention of post-traumatic stress disorder and the social usefulness of a psychiatric category. BMJ. 2001 Jan 13;322(7278):95-98.

25. Boyle M. Diagnosis. In: C. Newnes, G. Holmes, C. Dunn, editors. This is madness: a critical look at psychiatry and the future of mental health services. Ross-on-Wye: PCCS; 1999. p. 75-90.

26. Boyle M. The problem with diagnosis. Psychologist. 2007;20(5):290-2.

27. Kutchins H. and Kirk S. Making us crazy: DSM, the psychiatric bible and the creation of mental disorders. New York: Free Press; 1997.

28. Pilgrim D., Bentall R. The medicalisation of misery: A critical realist analysis of the concept of depression. J Ment Health. 1999 Jan;8:261-74.

29. Bentall R. Researching psychotic complaints. Psychologist. 2007;20(5):293-5.

30. Rapley M, Moncrieff J, Dillon J, editors. Demedicalising misery: psychiatry, psychology and the human condition. London: Palgrave Macmillan; 2011.

31. Rutter $M$ in Nemeroff CB, Weinberger D, Rutter R, MacMillan HL, Bryant RA, Wessely S, Stein DJ, Pariante CM, Seemüller F, Berk M, Malhi GS, Preisig M, Brüne M, Lysaker P. DSM-5: a collection of psychiatrist views on the changes, controversies, and future directions. BMC Med. 2013 Sep 12;11:202.

32. British Psychological Society. DSM-5: The future of psychiatric diagnosis: British Psychological Society response to the American Psychiatric Association. Leicester: BPS; 2012.

33. Galatzer-Levy IR, Bryant RA. 636,120 ways to have post-traumatic stress disorder. Perspect Psychol Sci. 2013 Nov;8(6):651-62.

34. Tol W, Barbui C, Galapatti A, Silove D, Betancourt TS, Souza R, Golaz A, van Ommeren M. Mental health and psychosocial support in humanitarian settings: linking practice and research. Lancet. 2011 Oct 29;378(9802):1581-91.

35. Kar N. Cognitive behavioral therapy for the treatment of post-traumatic stress disorder: a review. Neuropsychiatr Dis Treat. 2011;7:167-81.

36. Boynton PM, Greenhalgh T. Selecting, designing, and developing your questionnaire. BMJ. 2004 May 29;328:1312-5.

37. Hollifield M, Warner T, Lian N, Krakow B, Jenkins JH, Kesler J, Stevenson J, Westermeyer J. Measuring trauma and health status in a refugees: a critical review. JAMA. 2002 Aug 7;288(5):611-21.

38. Lund M, Sørensen JH, Christensen JB, Ølholm A. MTV om behandling og rehabilitering af PTSD - herunder traumatiserede flygtninge [Health technology assessment on the treatment and rehabilitation of PTSD - including traumatised refugees). Vejle: Published by Center for Quality, Southern Denmark; 2008.

39. Patel N, Kellezi B,Williams ACdeC. Psychological, social and welfare interventions for 
psychological health and well-being of torture survivors. Cochrane Database of Systematic Reviews 2011, Issue 10. Art.No.: CD009317. DOI: 10.1002/14651858.CD009317.

40. Neuner F, Schauer M, Klaschik C, Karunakara U, Elbert T. A comparison of narrative exposure therapy, supportive counseling, and psychoeducation for treating posttraumatic stress disorder in an African refugee settlement. J Cons Clin Psychol. 2004;72(4):579-87.

41. Difede JA, Cukor J, Jayasinghe N, Patt I, Jedel S, Spielman L, Giosan C, Hoffman HG. Virtual reality exposure therapy for the treatment of posttraumatic stress disorder following September 11, 2001. J Clin Psychiatry. 2007 Nov;68:1639-47.

42. Monson CM, Schnurr PP, Resick PA, Friedman MJ, Young-Xu Y, Stevens SP. Cognitive processing therapy for veterans with military-related posttraumatic stress disorder. J Consult Clin Psychol. 2006 Oct;74(5):898-907.

43. Rasmussen OV. Medical aspects of torture. Dan Med Bull. 1990 Jan;37 Suppl 1:1-88.

44. Thakker J, Ward T, Strongman KT. Mental disorder and cross-cultural psychology: a constructivist perspective. Clin Psychol Rev. 1999 Nov;19(7):843-74.

45. Gurr R, Quiroga J. Approaches to torture rehabilitation. Torture. 2001;11:5-35.

46. Hollifield M. Accurate measurement in cultural psychiatry: will we pay the costs? Transcult Psychiatry. 2002;39:419-21.

47. Newlands J, Patel N. Working with diversity: professional practice and ethical considerations. In: Trbe R, Morrissey J, editors. The handbook of professional and ethical practice for psychologists, counsellors and psychotherapists. East Sussex: Brunner-Routledge; 2004. P.233-46.

48. Bichescu D, Neuner F, Schauer M, Elbert T. Narrative exposure therapy for political imprisonment-related chronic posttraumatic stress disorder and depression. Behav Res Ther. 2007 Sep;45(9):2212-20.

49. Neuner F, Kurreck S, Ruf M, Odenwald M, Elbert T, Schauer M. Can asylum-seekers with posttraumatic stress disorder be successfully treated? A randomized controlled pilot study. Cogn Behav Ther. 2010;39(2):81-91.

50. Igreja V, Kleijn WC, Schreuder BJ, Van Dijk JA, Verschuur M. Testimony method to ameliorate post-traumatic stress symptoms. Communitybased intervention study with Mozambican civil war survivors. Br J Psychiatry. 2004 Mar;184:251-7.

51. Yeomans PD, Forman EM, Herbert JD, Yuen E. A randomized trial of a reconciliation work- shop with and without PTSD psychoeducation in Burundian sample. J Trauma Stress. 2010 Jun;23(3):305-12.

52. Arrindell WA. Changes in waiting-list patients over time: data on some commonly-used measures. Beware! Behav Res Ther. 2001 Oct;39(10):1227-47.

53. Paunovic N, Ost LG. Cognitive-behavior therapy vs exposure therapy in the treatment of PTSD in refugees. Behav Res Ther. 2001 Oct;39(10):1183-97.

54. Hensel-Dittmann D, Schauer M, Ruf M, Catani C, Odenwald M, Elbert T, Neuner F. Treatment of traumatized victims of war and torture : a randomized controlled comparison of narrative exposure therapy and stress inoculation training. Psychother Psychosom. 2011;80(6):345-52.

55. Schauer M, Elbert T, Gotthardt S, Rockstroh B, Odenwald $\mathrm{M}$, Neuner F. Wiedererfahrung durch Psychotherapie modifiziert Geistund Gehirn [Imaginary reliving in psychotherapy modifies mind and brain] Verhaltenstherapie. 2006;16(2):96103.

56. Cienfuegos J, Monelli C. The testimony of political repression as a therapeutic instrument. Am J Orthopsychiatry. 1983 Jan;53(1):43-51.

57. Mundt AP, Wunsch P, Heinz A, Pross C. Evaluating interventions for posttraumatic stress disorder in low and middle income countries: Narrative Exposure Therapy. Intervention. 2014 Jul;12(2):250-66.

58. Grey N, Young K. Cognitive behaviour therapy with refugees and asylum seekers experiencing traumatic stress symptoms. Behav Cog Psychother. 2008;36(1):3-19.

59. Clark DA, Beck AT. Cognitive therapy of anxiety disorders: science and practice. Guilford Press; 2011.

60. Robjant K, Fazel M. The emerging evidence for narrative exposure therapy: a review. Clin Psychol Rev. 2010 Dec;30(8):1030-9.

61. Miller KE, Davis JL. Book review: Narrative exposure therapy: a short-term treatment for traumatic stress disorders, by M Schauer, F Neuner, and T Elbert. J Trauma Dissociation. 2013;14:592-4.

62. McFarlane CA, Kaplan I. Evidence-based psychological interventions for adult survivors of torture and trauma: a 30 year review. Transcult Psychiatry. 2012;49:539-67.

63. Nickerson A, Bryant RA, Silove D, Steel Z. A critical review of psychological treatments of posttraumatic stress disorder in refugees. Clin Psychol Rev. 2010;39(3):399-417.

64. Stein DJ, Seedat S, Iversen A, Wessely S. Post- 
traumatic stress disorder: medicine and politics.

Lancet. 2007 Jan 13;369:139-44.

65. National Institute for Clinical Excellence

(NICE), Post traumatic stress disorder (PTSD).

The management of PTSD in adults and chil-

dren in primary and secondary care. National

Clinical Practice Guideline 26, 2005.

66. Wenk-Ansohn M. Treatment of torture survivors - influences of the exile situation on the course of traumatic process and therapeutic possibilities. Torture. 2007;17(2):88-95.

67. Ginzburg K, Neria Y. Mental health interventions for survivors of torture. Current status and future directions. J Psychol. 2011;219(3):187-9.

68. Bisson JI. Post-traumatic stress disorder. BMJ. 2007 Apr 14;334:789-93.

69. Basoglu M, Salcioglu E. A mental healthcare model for mass trauma survivors: control-focused behavioral treatment of earthquake, war and torture trauma. Cambridge: Cambridge University Press; 2011.

70. Goswami S, Rodriguez-Sierra O, Cascardi M, Pare D. Animal models of post-traumatic stress disorder: face validity. Front Neurosci. 2013 May 31;7:89.

71. Crumlish N, O'Rourke K. A systematic review of treatments for post-traumatic stress disorder among refugees and asylum seekers. J Nerv Ment Dis. 2010 Apr;198(4):237-51

72. Nicholl C, Thompson A. The psychological treatment of post traumatic stress disorder (PTSD) in adult refugees: a review of the current state of psychological therapies. J Ment Health. 2004; 13(4):351-62

73. Higgins JPT, Altman DG. Assessing risk of bias in included studies. In: Higgins JPT, Green S, editors. Cochrane handbook for systematic reviews of interventions, version 5.0.2 [updated 2009 Sept]. Available from www.cochrane-handbook.org.

74. Gaffan EA, Tsaquisis I, Kemp-Wheeler SM. Researcher allegiance and meta-analysis: the case of cognitive therapy for depression. J Consult Clin Psychol. 1995 Dec;63(6):966-80.

75. Johnson TP. Methods and frameworks for cross-cultural measurement. Med Care. 2006 Nov;44(11 Suppl 3):S17-20.

76. Sousa VD, Rojjanasrirat W. Translation, adaptation and validation of instruments or scales for use in cross-cultural health care research: a clear and user-friendly guideline. J Eval Clin Pract. 2011 Apr;17(2):268-74

77. Tanzer NK, Sim CQE. Adapting instruments for use in multiple languages and cultures: a review of the ITC guidelines for test adaptations. Eur J Psychol Assess 1999;15:258-69.
78. Vrana SR, Campbell TA, Clay R. Survey of national consortium of torture treatment program therapists about the assessment, diagnosis, and treatment of the psychological sequelae of torture. Traumatology. 2013;19(2):144-53.

79. Bittenbinder E, editor. Good practice in the care of victims of torture. Karlsruhe: Von Loeper Literaturverlag; 2010.

80. Bittenbinder E. Beyond statistics: sharing, learning and developing good practice in the care of victims of torture. Karlsruhe: Von Loeper Literaturverlag; 2012.

81. Patel N, Williams ACdeC. Monitoring and evaluation of rehabilitation services for torture survivors: Handbook for service providers. London: ICHHR; 2014.

82. Rousseau CT, Measham T, Nadeau L. Addressing trauma in collaborative mental health care for refugee children. Clin Child Psychol Psychiatry. 2013 Jan;18(1):121-36.

83. Pokhariyal GP, Rono R, Munywoki S. Analysis of treatment methods for victims of torture in Kenya and East Africa region. Traumatology 2013;19(2):107-17.

84. Ter Heide JJ, Mooren TM, Kleijn W, de Jongh A, Kleber RJ. EMDR versus stabilisation in traumatised asylum seekers and refugees: results of a pilot study. European Journal of Psychotraumatology. 2011;2:5881-92. 